\title{
BUSINESS ENGLISH: Como candidatar-se para uma vaga de emprego fora do Brasil ou em empresas multinacionais
}

BUSINESS ENGLISH: How to apply for a job outside Brazil or in multinational companies5

\author{
Francielly Rosa Marafon (10) \\ Universidade La Salle - Unilasalle - Rio Grande do Sul - Brasil
}

\author{
Vicente Henrique Brückmann Saldanha \\ Universidade do Vale do Rio dos Sinos - Unisinos - Rio Grande do Sul - Brasil
}

\author{
Maria Alejandra Saraiva Pasca
}

Universidade La Salle - Unilasalle - Rio Grande do Sul - Brasil

\begin{abstract}
Resumo: Este artigo tem como objetivo expor as atividades, experiências e informações observadas e coletadas em sala de aula virtual de inglês de maio a agosto de 2020. Considerando a pandemia atual em virtude do novo Coronavírus, nos encontramos em situação grave de isolamento social. Por isso, o curso livre Idiomas Four, localizado em Canoas/RS, passou a utilizar ferramentas da plataforma online Google, como o Hangouts e o Google Meet para a realização de aulas síncronas. O projeto aqui descrito foi aplicado em uma turma de adultos de nível intermediário de inglês, com atividades e conteúdo que contemplam o vocabulário e as formalidades do inglês para negócios, como por exemplo, entrevistas de emprego, currículos, cartas de apresentação. Além de trabalhar o vocabulário de inglês para negócios, o objetivo do projeto era motivar os estudantes a melhorar sua produção e compreensão oral na língua inglesa. Após a aplicação do projeto, observou-se o progresso significativo dos alunos quanto a sua produção oral e escrita formal, como também uma maior familiarização do grupo com questões que envolvem concorrer a vagas de emprego que exigem o conhecimento da língua inglesa.
\end{abstract}

Palavras-chave: Aulas Online. Compreensão oral. Inglês para negócios. Produção oral.

Resumen: This article presents the activities, experiences and information observed and collected in the virtual classroom from May to August, 2020. Considering the current pandemic due to the new Coronavirus, we are in a serious situation of social isolation. For this reason, Idiomas Four language course, located in Canoas/RS, started to use tools from the Google online platform, such as Hangouts and Google Meet, to perform synchronous classes. The project described here was applied to a group of intermediate English adult learners, with activities and content that included the vocabulary and formalities of Business English, such as job interviews, resumes, and cover letters. In addition to working with business English vocabulary, the aim of the project was to motivate students to improve their oral comprehension and production in English. After the application of the project, it was possible to see students' significant progress in oral and written production, as well as a greater familiarization of the group with issues that involve applying for job openings that require English knowledge.

Key words: Online classes. Oral comprehension. Business English. Oral production. 


\section{Introdução}

Através das observações de aula no curso livre Idiomas Four, localizado na cidade de Canoas/RS, foi possível notar a insegurança dos alunos da turma de inglês intermediário de falar a segunda língua (L2). Uma vez que esses estudantes estão se encaminhando para o nível avançado e considerando o seu interesse em adquirir vocabulário para o ambiente de trabalho multinacional, 0 projeto "Business English: como candidatar-se a uma vaga de emprego fora do Brasil ou em empresas multinacionais" teve como objetivo principal desenvolver a autoconfiança dos aprendizes na habilidade de fala na língua inglesa. O projeto, apresentado na disciplina de Estágio IV do Curso de Letras na Universidade La Salle - Canoas, baseou-se na Pedagogia de Projetos, que vem auxiliando as disciplinas de inglês de forma significativa, pois oportuniza ao acadêmico vivenciar a realidade, interpretando-a, por meio da observação e da adequação entre a teoria estudada em sala de aula e a prática (ALVARELI e COELHO, 2017).

As competências pretendidas com 0 projeto foram as seguintes: desenvolver melhor a confiança e segurança ao falar a língua inglesa; desenvolver as habilidades de fala e escrita formal no segundo idioma; interessar-se na possibilidade de trabalhar fora do país em empresas multinacionais; desenvolver a habilidade auditiva assistindo vídeos relacionados ao inglês para negócios. $\mathrm{O}$ estudo teve como embasamento teórico o artigo Gold Standard PBL: Essential Project Design Elements, do Instituto Buck de Educação, publicado em 2015, no qual o foco é preparar os alunos para uma vida acadêmica com êxito e experiências de vida. Em virtude disso, o projeto foi pensado para os estudantes adultos que têm vontade de tentar uma vida profissional no exterior, mas têm dificuldade nas habilidades de fala em inglês. Além disso, o interesse em aplicar a Pedagogia de Projetos justifica-se porque envolve os alunos em resolução de desafios, inspirando-os a buscar um conhecimento mais profundo sobre os assuntos que estão estudando (ALVARELI e
COELHO, 2017). Ela também faz com que o professor aborde de maneira dinâmica o ensino e a aprendizagem, explorando problemas do mundo real e adotando uma mudança de postura e forma de condução das ações em sala de aula. $O$ docente valoriza o trabalho coletivo e ações conjuntas que propiciem $\mathrm{o}$ desenvolvimento de atividades $\mathrm{e}$ viabilizem o espírito participativo e comprometido dos educandos (FREITAS et al., 2003).

\section{PROJETO PEDAGÓGICO}

Considerando a insegurança dos alunos ao se expressarem em inglês, pensei, como estagiária de Letras, em formas de desinibir os alunos quanto às habilidades de fala nessa turma, propondo um projeto no qual os estudantes pudessem candidatar-se a uma entrevista de emprego para trabalhar fora do Brasil. A ideia era que adquirissem o conhecimento de novas palavras relacionadas ao inglês para negócios, pois segundo Somjai e Soontornwipast (2020), o vocabulário auxilia na comunicação, sendo considerado um dos aspectos essenciais no aprendizado de idiomas, especialmente em inglês como segunda língua ou língua estrangeira (ESL/EFL). Além disso, os alunos foram solicitados a fazer como produto final a gravação de um vídeo currículo.

Práticas mais próximas da realidade vivenciadas pelo aprendiz podem servir como possiblidades de superar distúrbios de aprendizagem, desmotivação, bloqueio ou resistência à aprendizagem da língua inglesa. Essa forma de trabalho abre espaço para os professores se aproximarem e se relacionarem de forma produtiva com os alunos, realizando um trabalho colaborativo de compromisso educativo em que todos ensinam, aprendem e compartilham conhecimento (ALVARELI e COELHO, 2017).

Como base para a implementação do projeto, foi utilizada a Pedagogia de Projetos, que é:

uma mudança de postura pedagógica fundamentada na concepção de que a aprendizagem ocorre a partir da resolução de situações didáticas significativas para 0 aluno, 
aproximando-o o máximo possível do seu contexto social, através do desenvolvimento do senso crítico, da pesquisa e da resolução de problemas (FREITAS, 2003, p.17-37).

O estudo da Pedagogia de Projetos é importante no ambiente educacional universitário pois este deve ser dinâmico, inovador, e adaptado sempre que possível para manter atenção, empenho, e interesse dos aprendizes enquanto estudam, já que futuros docentes estão sendo preparados para atender às necessidades dos alunos de inglês do século 21 . Essa forma de ensino oferece suporte a habilidades de pensamento de alto nível, influenciando positivamente 0 desenvolvimento linguístico e acadêmico dos estudantes de inglês. A natureza interativa e colaborativa da pedagogia de projetos apoia o desempenho dos alunos de inglês na sala de aula e além (ALMAGUER, DIAZ e ESQUIERDO, 2015).

O projeto descrito neste artigo foi desenvolvido de acordo com o modelo disponibilizado pelo Instituto Buck de Educação em 2015, Gold Standard PBL: Essential Project Design Elements, no qual o professor divide o estudo em três partes: os objetivos de aprendizagem do aluno, os elementos essenciais do projeto e o projeto baseado em práticas pedagógicas. De acordo a publicação, os alunos aprendem como aplicar no mundo real o que aprenderam na escola, utilizando isso para a solução de problemas, respostas de perguntas complexas e criação de produtos de alta qualidade.

\section{CRITÉRIOS DE AVALIAÇÃO E RECURSOS NECESSÁRIOS PARA O PROJETO}

A avaliação do processo de ensino e aprendizagem pretendia ser feita de maneira formativa, como citada no artigo Gold Standard PBL: Essential Project Design Elements, fazendo com que os alunos produzissem melhor com o suporte da pesquisa e do material disponibilizado. Foi explicado aos alunos que a nota final não seria apenas o que o professor observou durante a aplicação do projeto, mas também como os alunos avaliaram os resultados do próprio aprendizado, através das apresentações orais e do produto final. Nessa avaliação, seria dada especial atenção à entonação, pronúncia e à estrutura gramatical, assim como à compreensão mútua entre os alunos ao entrevistarem os colegas, à escrita formal de emails para vagas de trabalho em empresas e à escrita de currículos. Todas essas questões precisavam ser levadas em conta na avaliação, pois

\begin{abstract}
fazer com que os alunos participem e colaborem de maneira efetiva, bem como a forma de avaliar a sua participação e o seu desempenho em sala de aula são desafios a serem enfrentados no cotidiano daqueles que se propõem a trabalhar com projetos (ALVARELI e COELHO, 2017, p.14).
\end{abstract}

Os recursos necessários para a aplicação das aulas do projeto foram computadores com acesso à internet; anúncios de vagas de emprego disponibilizados na internet; exemplos de currículos; exemplos de e-mails formais; o jogo de cartas Play to Learn: Questions for Business English; vídeos do Youtube com entrevistas de emprego; câmera digital ou celular para gravação de vídeo; computador e/ou celular para a edição de vídeos.

\section{PRÁTICA}

As observações das aulas desse grupo de alunos em que o projeto pedagógico foi aplicado foram feitas presencialmente no turno da noite em março de 2020, mas a prática pedagógica ocorreu online, via Google Meet, devido à necessidade de isolamento social em razão da Covid 19. As aulas foram tranquilas e a comunicação alternou o uso de português brasileiro (PB) e do inglês devido a leituras de textos informativos em PB. No entanto, as discussões sempre foram realizadas na L2. Os alunos foram participativos em todas as aulas, realizando as atividades propostas com interesse. O objetivo do projeto de tentar desinibi-los na produção oral em língua inglesa foi alcançado com sucesso.

$\mathrm{Na}$ primeira aula, conversamos sobre as possibilidades e o interesse da turma em viajar para buscar uma carreira em outro país. A aluna mais 
nova, de 18 anos, comentou não ter experiência profissional até o momento. Os outros alunos comentaram não ter interesse em buscar emprego em outros países. A aluna de 33 anos, que trabalha em uma empresa multinacional, comentou sobre os benefícios de saber um segundo idioma para trabalhar na sua empresa, como oportunidades de ser promovida. Fizemos a leitura e discussão sobre um artigo escrito por Discacciati (2019) sobre como é trabalhar no exterior, quais são as vantagens dessa experiência e como é possível conseguir emprego fora do Brasil. Na segunda aula do projeto, os alunos fizeram buscas online e analisaram diferentes vagas de empregos que exigem o conhecimento da língua inglesa, além de exemplos de currículos em inglês.

Após a análise de vagas de emprego, currículos e vídeos sobre como se comportar em entrevistas, na terceira aula, os alunos leram um artigo sobre como preparar um currículo para empresas multinacionais ou para empregos fora do país e criaram o seu próprio. Na mesma aula, os alunos assistiram a um vídeo sobre como escrever emails formais para superiores tais como orientadores, chefes e coordenadores, e colocaram em prática o que tinham aprendido escrevendo um e-mail semelhante ao do vídeo.

$\mathrm{Na}$ quarta aula, os alunos assistiram a outro vídeo sobre como se comportar em uma entrevista de emprego e responderam às perguntas mais frequentes nessas entrevistas. A atividade foi planejada para melhorar as habilidades de compreensão oral dos alunos. Essa aula foi descontraída e houve grande participação dos alunos assim como na aula seguinte, de simulação de emprego. A partir desse momento, o grupo começou a demonstrar certa tranquilidade ao falar em inglês, sem tanta resistência como nas aulas anteriores.

$\mathrm{Na}$ quinta aula, os alunos simularam uma entrevista de emprego entre os colegas com o auxílio do jogo de cartas Play to Learn: Questions for Business English. Os estudantes sentiram-se à vontade para questionar os colegas e foram criativos e cuidadosos ao utilizar o inglês de maneira mais formal para as entrevistas, pois sabiam que deviam considerar o colega entrevistador como alguém que realmente poderia contratá-los.

Para iniciar e organizar a produção do produto final do projeto, na sexta aula, os alunos assistiram a um "vídeo currículo", uma vez que atualmente, após selecionarem os candidatos, é comum que algumas empresas solicitem um vídeo no qual eles devem se apresentar, falar um pouco de si, sobre os objetivos pessoais e profissionais e por que deveriam ser contratados para a vaga. Na última aula, para minha avaliação, os alunos apresentaram seus vídeos como produto final, compartilharam sua experiência durante a produção e relataram o quanto o projeto foi útil para o seu crescimento profissional. Esses depoimentos foram levados em conta para avaliar os aprendizes juntamente com toda a produção durante o projeto.

Como professora estagiária de Letras, observei dificuldades individuais durante o processo. Por estar iniciando a carreira profissional, a aluna mais jovem, de 18 anos, não sabia como contribuir nos momentos em que trocávamos experiências. Assim, foi necessário adaptar algumas perguntas tanto nas entrevistas como nos debates em aula para que ela pudesse participar mais ativamente. Os outros três adultos da turma demonstraram resistência na leitura dos artigos e dificuldades de pronúncia nas primeiras aulas, mas no decorrer do projeto, com as adaptações, demonstraram-se interessados pelo conteúdo apresentado, principalmente pelas entrevistas.

\section{CONCLUSÃO}

A oportunidade de estagiar durante a graduação é uma das mais importantes no decorrer da formação de futuros professores de língua inglesa, pois é o momento em que eles descobrem se realmente querem exercer a docência nos anos seguintes. Essas práticas também preparam o futuro professor para o que pode encontrar não só em sala de aula regular, mas também em cursos livres de idiomas, e outros espaços de ensino no início da sua carreira como profissional da educação. 
No estágio, o uso da pedagogia de projetos possibilitou aos aprendizes

usarem a língua inglesa em sala de aula simulando situações que podem futuramente serem aplicadas na vida profissional. No entanto, houve desafios durante a trajetória do projeto. O maior deles foi pensar em algo que motivasse os alunos a terem segurança ao falar em inglês, tirando-os da zona de conforto. O Inglês para Negócios foi aplicado aliado à pedagogia de projetos para motivar os aprendizes adultos a terem mais confiança na sua produção oral. Auxiliar a aluna mais jovem, que não estava tão familiarizada quanto os outros colegas com o mercado de trabalho, também foi desafiador. Em alguns momentos nos quais compartilhávamos experiências profissionais, foi necessário fazer adaptações para que ela também tivesse a oportunidade de participar, como por exemplo, criando situações imaginárias sobre aquele cenário.

Apesar dos desafios, os resultados foram satisfatórios porque os estudantes adultos adquiriram novo vocabulário, que poderá ser utilizado não somente em sala de aula, mas também em experiências profissionais reais. Além disso, familiarizaram-se com a escrita e a fala formal e consideraram a possibilidade de uma vida profissional fora do Brasil.

Acompanhar a evolução dos alunos e a turma demonstrando confiança ao falar em inglês foi uma experiência única e gratificante como estagiária. Esta foi a primeira vez que o projeto foi aplicado na escola de idiomas, mas havendo interesse de outras turmas de adultos, pode ser replicado em outros semestres. Para que fique mais completo, seria interessante acrescentar ao projeto atividades extras de compreensão oral nas quais os alunos recebam mais informações de vocabulário específico de negócios, aprimorando ainda mais a fala por meio de práticas auditivas.

\section{REFERÊNCIAS}

ALMAGUER, Isela; DIAZ, Zulmaris; ESQUIERDO, J. Joy. Project-Based Learning:
Innovative Pedagogy for 21st-Century English Learners. Teacher Education \& Practice. Scarecrow Press Inc. 2015, 14 p.

ALVARELI, Luciani Vieira Gomes; COELHO, Taciana Oliveira Carvalho. Pedagogia de Projetos: Práticas Bem-Sucedidas em Aulas de Inglês. v.1 n.1. FATEC Cruzeiro / UNIFATEA Lorena e FATEC Guaratinguetá, 2017. 21 p.

AUSTIN, Heather. How to Write a Professional Email - 4 Professional Email Writing Tips Disponível em:

<https://www.youtube.com/watch?v=VQNK38iKRxk> Acesso em: 01 jul. 2020.

CASTRO, Mariangela. Como montar um currículo para trabalhar fora do Brasil Disponível em: <https://www.infomoney.com.br/carreira/comomontar-um-curriculo-para-trabalhar-fora-do-brasil/> Acesso em: 24 jun. 2020.

DISCACCIATI, Julia. Trabalhar no exterior: saiba como é, se vale a pena e como conseguir. Disponível em: <https://www.eurodicas.com.br/trabalhar-no-exterior/> Acesso em: 20 maio 2020.

FREE ENGLISH LESSONS, Learn English with Let's Talk. 08 common Interview question and answers - Job Interview Skills Disponível em: $<$ https://www.youtube.com/watch?v=1mHjMNZZvFo> Acesso em: 08 jul. 2020.

GASPARINI, Claudia. 11 sites e aplicativos para encontrar vagas de emprego. Disponível em: <https://exame.com/carreira/11-sites-e-aplicativospara-procurar-emprego/> Acesso em: 24 jun. 2020.

Gold Standard PBL: Essential Project Design Elements. Buck Institute for Education, 2015. Disponível em acesso em: https://www.pblworks.org/blog/gold-standard-pblessential-project-design-elements 
LEARNING ENGLISH, BBC. Writing an email 18 - English at Work has the words for perfect emails. Disponível em: <https://www.youtube.com/watch?v=aO3Det4ir8U> Acesso em: 01 jul. 2020.

\section{LERUSTE, Mark. BEST VIDEO CV EVER: MARK LERUSTE. Disponível em:} <https://www.youtube.com/watch?v=c_PZTAW5piQ> Acesso em: 22 jul. 2020.

MARTINS, Camila. 10 carreiras de sucesso para quem fala inglês - Portal Carreira \& Sucesso Disponível em: <https://www.catho.com.br/carreirasucesso/colunistas/noticias/10-carreiras-de-sucessopara-quem-fala-ingles> Acesso em: 24 jun. 2020.

ROCHA, Augusto. Diferença entre Currículo e Carta de Apresentação. Disponível em: <https://outliers.com.br/2017/05/08/a-principaldiferenca-entre-um-cv-e-uma-carta-de-apresentacao> Acesso em: 01 jul. 2020.

SOMJAI, Satit; SOONTORNWIPAST, Kittitouch. The Integration of Implicit and Explicit Vocabulary Instruction, Project-Based Learning, Multimedia, and Experiential Learning to Improve Thai EFL Senior High School Students' Vocabulary Ability. 6. ed. Bangkok, Thailand, Language Institution, Thammasat University, 2020, 21 p.

\section{COMO CITAR ESSE ARTIGO}

MARAFON, Francielly Rosa; SALDANHA, Vicente Henrique Brückmann; PASCA, Maria Alejandra Saraiva. Business english: Como candidatar-se para uma vaga de emprego fora do Brasil ou em empresas multinacionais. Signo, Santa Cruz do Sul, v. 46, n. 85, p. 278-283, jan. 2021. ISSN 1982-2014. Disponível em: $<$ https://online.unisc.br/seer/index.php/signo/article/view/15664>.doi:https://doi.org/10.17058/signo.v46i85.15664. 